\title{
Pleural Space Elastance and Its Relation to Success Rates of Pleurodesis in Malignant Pleural Effusion
}

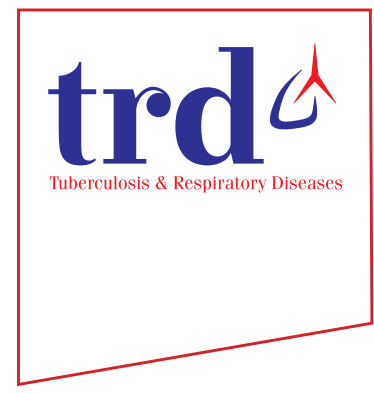

\author{
Hossam Hosny Masoud, M.D. ${ }^{\circledR}$, Mahmoud Mohamed El-Zorkany, M.D., Azza Anwar Ahmed, M.Sc. \\ and Hebatallah Hany Assal, M.D. (1)
}

Department of Chest Medicine, Faculty of Medicine, Cairo University, Cairo, Egypt

Background: Pleurodesis fails in $10 \%-40 \%$ of patients with recurrent malignant pleural effusions malignant pleural effusion and dyspnea. This study aimed to assess the values of pleural elastance $\left(\mathrm{P}_{\mathrm{EL}}\right)$ after the aspiration of $500 \mathrm{~mL}$ of pleural fluid and their relation to the pleurodesis outcome, and to compare the pleurodesis outcome with the chemical characteristics of pleural fluid.

Methods: A prospective study was conducted in Kasr El-Aini Hospital, Cairo University, during the period from March 2019 to January 2020. The study population consisted of 40 patients with malignant pleural effusion. The measurement of $\mathrm{P}_{\mathrm{EL}}$ after the aspiration of $500 \mathrm{~mL}$ of fluid was done with " $\mathrm{P}_{\mathrm{EL}} 0.5$ " $\left(\mathrm{cm} \mathrm{H}_{2} \mathrm{O} / \mathrm{L}\right)$, and the characteristics of the pleural fluid were chemically and cytologically analyzed. Pleurodesis was done and the patients were evaluated one month later. The $\mathrm{P}_{\mathrm{EL}}$ values were compared with pleurodesis outcomes.

Results: After 4-week of follow-up, the success rate of pleurodesis was $65 \%$. The $\mathrm{P}_{\mathrm{EL}} 0.5$ was significantly higher in failed pleurodesis than it was in successful pleurodesis. A cutoff point of $\mathrm{P}_{\mathrm{EL}} 0.5>14.5 \mathrm{~cm} \mathrm{H}_{2} \mathrm{O} / \mathrm{L}$ was associated with pleurodesis failure with a sensitivity and specificity of $93 \%$ and $100 \%$, respectively. The patients with failed pleurodesis had significantly lower $\mathrm{pH}$ levels in fluid than those in the successful group $(\mathrm{p}<0.001)$.

Conclusion: $\mathrm{P}_{\mathrm{EL}}$ measurement was a significant predictor in differentiating between failed and successful pleurodesis. The increase in acidity of the malignant pleural fluid can be used as a predictor for pleurodesis failure in patients with malignant pleural effusion.

Keywords: Pleural Elastance; Malignant Pleural Effusion; Pleurodesis

\section{Introduction}

Address for correspondence: Hebatallah Hany Assal, M.D.

Department of Chest Medicine, Faculty of Medicine, Cairo University, Al Kasr Al Aini, Old Cairo, Cairo 11956, Egypt

Phone: 20-1223939861, Fax: 20-38642085

E-mail: Hebatallah.Assal@kasralainy.edu.eg

Received: Jul. 23, 2020

Revised: Sep. 28, 2020

Accepted: Nov. 9, 2020

Published online: Nov. 9, 2020

(c) It is identical to the Creative Commons Attribution Non-Commercial License (http://creativecommons.org/licenses/by-nc/4.0/).
Malignant pleural effusion (MPE) presents a severe medical condition that can result in breathlessness, pain, cachexia, and reduced physical activity. Epidemiological information is limited, but an estimated 50,000 new diagnoses of MPE are made in the UK each year ${ }^{1}$. The incidence of MPE is likely to rise as global cancer incidence increases and overall survival improves ${ }^{2}$.

Pleurodesis or achievement of pleural symphysis preventing the need for repeated pleural fluid drainage is the cornerstone of palliative treatment in this population ${ }^{3}$. Successful pleurodesis requires the visceral and parietal pleural to maintain physical contact while sclerosant agent is infused ${ }^{3}$.

Non-expandable lung (NEL) that is usually assessed by chest radiography points out the predicted outcome of failed 
pleurodesis due to inability of the visceral and parietal pleura to contact. Therefore, NEL is considered to be an absolute contraindication for pleurodesis. The pleural manometry (PM) which is the direct measurement of pressure in the pleural space through a catheter appears to be a promising modality for predicting lung expansion post pleural fluid drainage ${ }^{3}$.

Pleural elastance $\left(\mathrm{P}_{\mathrm{EL}}\right)$ which is the change in pleural liquid pressure in $\mathrm{cm} \mathrm{H}_{2} \mathrm{O}$ per liter of fluid removed, reflects the ability of the underlying lung to freely expand as the pleural fluid being removed. In other words, higher values of $\mathrm{P}_{\mathrm{EL}}$ (more pressure change per a given volume of fluid removed) indicates an underlying stiff lung and vice versa ${ }^{3}$.

Pleural manometry was proven to be the method of choice for detecting an un-expandable lung $^{4}$.

This highlights the need for PM data to understand pleural pathophysiology better to optimize care for MPE patients.

The current study aimed to assess the values of $\mathrm{P}_{\mathrm{EL}}$ after aspiration of $500 \mathrm{~mL}$ of pleural fluid $\left(\mathrm{P}_{\mathrm{EL}} 0.5\right)$ and its relation to pleurodesis outcome, also to compare the pleurodesis outcome with chemical characteristics of pleural fluid.

\section{Materials and Methods}

A prospective cross-sectional study was conducted in Kasr El-Aini hospital, Cairo University, from March 2019 to January 2020.

\section{Population}

It was carried on 40 patients, 22 male patients and 18 female patients. The study was approved by the institutional review board at Kasr Al-Aini Hospital, Cairo University (IRB \#D-32019) and informed consent was obtained from all enrolled patients. Patients with MPE who agreed to participate were included in the study. Exclusion criteria were as follows: 1, very small amount of pleural effusion; 2, multi-loculated malignant pleural effusion; 3, patients with type II respiratory failure; 4, patients presenting with major organ failure; and 5, patients who have bleeding disorders that interfere with thoracocente- sis and pleural biopsy.

Patients were examined by B-mode transthoracic ultrasound with curvilinear transducer $(3.5 \mathrm{MHz})$ to assess the pleura before thoracoscopy regarding the presence of pleural thickening, nodulations, adhesions, septations, or encystations (Hitachi 5500, Tokyo, Japan).

\section{Measurement of pleural pressure}

The patient was sitting with his arms on the back of the chair, causing the intercostal spaces to be extended and to facilitate access. The skin was cleaned with betadine antiseptic solution. Lidocaine $2 \%(5-10 \mathrm{~mL})$ was given as local anesthetic in the site of puncture. One milligram of atropine was injected intramuscularly. The needle was inserted under sonographic guidance.

Thoracocentesis was performed for all patients with the use of wide-bore catheter and IV sets. As shown in Figure 1A, the measurement of pleural pressure was done by a simple water column manometer that designed for measuring central venous pressure. The water manometer consists of two lengths of intravenous tubing connected through a three-way valve to a wide-bore catheter inserted in the pleural space. The tubing from the thoracocentesis catheter to the measuring scale extends 40 to $50 \mathrm{~cm}$ below the level of the catheter insertion into the chest similar to a U-shaped water manometer. The system (IV tubing) is purged of air with normal saline. Zero value was set at the thoracic puncture level. After pressure recording, the water manometer described above was removed. As shown in Figure 1B, the catheter was connected to a fluid drainage bag through IV tubing for drainage. Initial pleural pressure was measured before removing any fluid and after the removal of $500 \mathrm{~mL} . \mathrm{P}_{\mathrm{EL}}$ was calculated $\left(\mathrm{P}_{\mathrm{EL}}=\right.$ change in pleural liquid pressure in $\mathrm{cm} \mathrm{H}_{2} \mathrm{O}$ per liter of fluid removed). $\mathrm{P}_{\mathrm{EL}} 0.5$ is referred to the $\mathrm{P}_{\mathrm{EL}}$ while the first $0.5 \mathrm{~L}$ of fluid is aspirated. After measuring $\mathrm{P}_{\mathrm{EL}}$ medical thoracoscopy was done for tissue biopsy and intercostal tube was inserted. When the amount of drained fluid decrease to $100 \mathrm{~mL}$ or less per day, lung radiologically reexpanded against the chest wall by chest X-ray (CXR) and biopsies proved to be malignant, chemical pleurodesis was done.
A

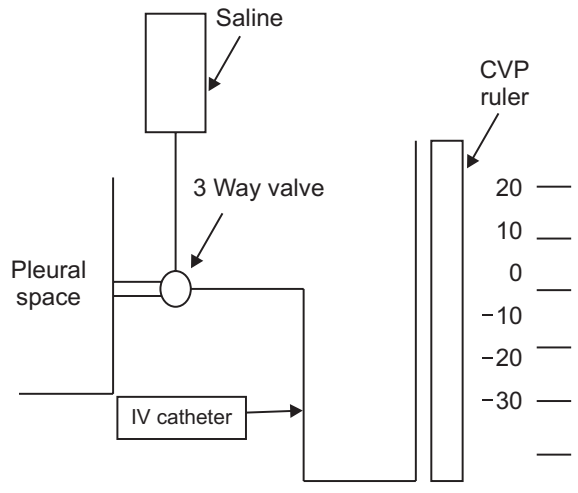

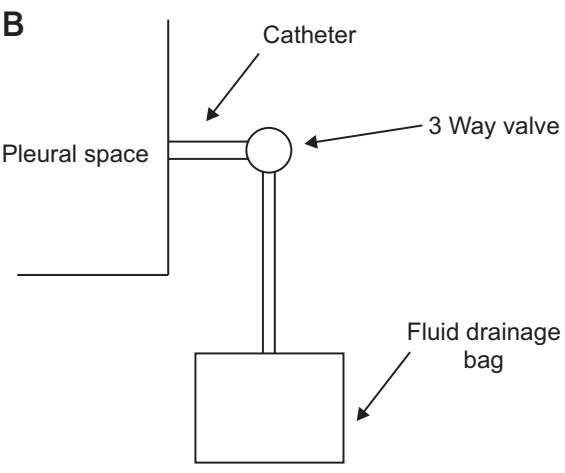

Figure 1. A schematic diagram representing the setup of pleural manometry. CVP: central venous pressure. 


\section{Method of chemical pleurodesis}

One milligram of atropine was injected intramuscularly to control vasovagal tone. Injection of $20 \mathrm{~mL}$ of $2 \%$ lidocaine into the pleural space through the intercostal tube. Injection of the sclerosing agent doxycycline (vibramycin), $15-20 \mathrm{mg} / \mathrm{kg}$ dissolved into $50 \mathrm{~mL}$ of normal saline injected into the pleural space through the tube followed by $20 \mathrm{~mL}$ of normal saline to flush the chest tube. Clamping the chest tube for 2 hours, after that the tube was opened. The chest tube was removed when the drainage was less than $150 \mathrm{~mL} / 24$ hours and a chest X-ray was obtained.

\section{Assessment of success}

At the end of the 4-week follow-up period, the radiographic response (CXR) was classified as follows: A, successful: if no radiographic evidence of fluid re-accumulation was noted at 4 weeks; B, partial successful: indicated re-accumulation of fluid that did not produce symptoms and did not require repeat pleural drainage of any sort. A or B considered to be in the successful group; $\mathrm{C}$, all other outcomes were scored as failed.

\section{Statistical methods}

The data collected tabulated and statistically analyzed using Minitab 17.1.0.0 for windows (Minitab Inc., State College, PA, USA), by the following methods: (1) descriptive statistics: continuous data were represented as mean and standard deviation (SD), while non-numerical data as number and percentage (\%); (2) analytic statistics: independent t test: used to compare mean of two independent groups; person chi-square test: used to test the association between categorical variables.

All statistical tests were two-sided, p-value considered significant if $<0.05$.

\section{Results}

The mean age of the studied patients was $60.98 \pm 10.32$ years old. They were 22 males (55\%) and 18 females (45\%). Eighteen patients (45\%) were smokers. All patients presented by dyspnea either alone $(70 \%)$ or with chest pain (30\%). Twelve patients $(30 \%)$ were diabetics.

Pleural fluid biochemical analysis as regarding mean and SD was as follows: albumin $2.45 \pm 0.61 \mathrm{~g} / \mathrm{dL}$, protein $4.46 \pm 1.01$ $\mathrm{g} / \mathrm{dL}$, lactate dehydrogenase (LDH) $603.4 \pm 517 \mathrm{IU} / \mathrm{L}, \mathrm{pH}$ $7.33 \pm 0.11$, glucose $100.2 \pm 66.3 \mathrm{mg} / \mathrm{dL}$.

Radiological examination revealed that most of the patients (52.5\%) had right-side pleural effusion. The mean value of $\mathrm{P}_{\mathrm{EL}}$ $0.5\left(\mathrm{~cm} \mathrm{H}_{2} \mathrm{O} / \mathrm{L}\right)$ was 11.85 and 5.88 (SD) with range (4-24).

Macroscopic findings that were encountered during thoracoscopy were as follows: pleural masses in five patients
(12.5\%), thickened pleura in four patients (10\%). Pleural nodules were the commonest feature either alone in 20 patients $(50 \%)$ or associated with thick pleura in 11 patients $(27.5 \%)$. Regarding pleural fluid cytological exam: malignant cells were found in 10 patients (25\%), 10 patients (25\%) had predominant lymphocytes, four patients (10\%) had predominant mesothelial cells, while no obvious predominant cell in cytological examination where found in 16 patients $(40 \%)$.

Finally, the histopathological diagnosis revealed malignant mesothelioma in 26 patients (65\%) while 14 patients (35\%) had metastatic tumors, nine patients (22.5\%) had metastatic adenocarcinoma of breast origin, two patients $(5 \%)$ had poorly differentiated adenocarcinoma. Three patients $(7.5 \%)$ had metastatic adenocarcinoma from the lung, one patient $(2.5 \%)$ had metastatic non-small cell lung cancer, one patient (2.5\%) had metastatic small cell lung cancer, and one patient (2.5\%) had metastatic high-grade squamous cell carcinoma.

More than half of the patients had no complications after pleurodesis. There was pain in 12 patients (30\%), infection in four patients (10\%) in whom antibiotics were received according to culture and sensitivity and surgical emphysema in one patient $(2.5 \%)$.

The patients were then classified into two groups regarding the pleurodesis outcome 1 month later, depending on CXR finding, to find the associated factors that precipitated the failure of pleurodesis.

Fourteen out of 40 patients were failed to pleurodesis (35\%) and 26 out of $40(65 \%)$ had successful pleurodesis based on radiological assessment after 1 month as described above.

No impact of age, sex, and smoking habits on pleurodesis

Table 1. Impact of patient's demography and pleural fluid characteristics on pleurodesis outcome

\begin{tabular}{|lccc|}
\hline \multicolumn{1}{|c}{ Variable } & $\begin{array}{c}\text { Failed } \\
\text { pleurodesis }\end{array}$ & $\begin{array}{c}\text { Successful } \\
\text { pleurodesis }\end{array}$ & p-value \\
\hline Age, yr & $63.6 \pm 10.1$ & $59.6 \pm 10.3$ & $0.24^{*}$ \\
Sex & & & $0.84^{\dagger}$ \\
\hline Female & $6(42.9)$ & $12(46.2)$ & \\
Male & $8(57.1)$ & $14(53.9)$ & \\
Smoking & & & $0.64^{\dagger}$ \\
No & $7(50)$ & $15(57.7)$ & \\
Yes & $7(50)$ & $11(42.3)$ & \\
Complain duration, mo & $2.14 \pm 1.74$ & $2.5 \pm 1.95$ & $0.55^{*}$ \\
Effusion location & & & $0.66^{\dagger}$ \\
Left & $6(42.9)$ & $13(50)$ & \\
Right & $8(57.1)$ & $13(50)$ & \\
\hline
\end{tabular}

Values are presented as mean \pm standard deviation or number $(\%)$. ${ }^{*}$ Independent $\mathrm{t}$ test. ${ }^{\dagger} \mathrm{Chi}$-square test, $\mathrm{p}$-value considered significant if $<0.05$. 
outcome ( $\mathrm{p}=0.24, \mathrm{p}=0.84$, and $\mathrm{p}=0.64$ ) respectively (Table 1 ). There was no impact of complain duration nor location of pleural effusion on pleurodesis outcome $(\mathrm{p}=0.55, \mathrm{p}=0.66$, and $\mathrm{p}=0.53$ ), respectively (Table 1 ). There was no significant statistical difference between the two groups except in pleural fluid $\mathrm{pH}$, which was significantly lower in the failed pleurodesis group (Table 2). $\mathrm{P}_{\mathrm{EL}} 0.5\left(\mathrm{~cm} \mathrm{H}_{2} \mathrm{O} / \mathrm{L}\right)$ was significantly higher in group with failed pleurodesis $(m e a n \pm S D, 18.29 \pm 4.65)$ than the successful group (mean $\pm S D, 8.38 \pm 2.65)(p<0.001)$ (Figure 2).

The receiver operating characteristic curve showed that the $\mathrm{P}_{\mathrm{EL}}$ was a significant predictor measure in differentiating between failed and successful pleurodesis (area under the curve [AUC] $94 \%, \mathrm{p}<0.001$ ). At cutoff point $>14.5$, the sensitivity and specificity were $93 \%$ and $100 \%$, respectively (Figure 3 ).

The patients with successful pleurodesis consumed significantly shorter duration of intercostal tune insertion with $6.08 \pm 1.6$ days (mean $\pm S D$ ) than the failed one $10.64 \pm 2.92$ days $($ mean $\pm S D)(p<0.001)$.

\section{Discussion}

An unexpandable lung in MPE causes pleurodesis failure but is difficult to detect predrainage. Measurement of $\mathrm{P}_{\mathrm{EL}}$ has been shown as an attractive tool to predict unexpandable lung in malignant pleural effusion. However, due to technical limitations it has been underutilized in the clinical practice. In the past years, little attention has been paid to the measurement of $\mathrm{P}_{\mathrm{EL}}$ before pleurodesis. Most of the trials use radiographic lung expansion as a surrogate for normal pleural physiology.

In our study, we measured $\mathrm{P}_{\mathrm{EL}}$ in 40 patients with MPE during aspiration of $500 \mathrm{~mL}$ of fluid and compared it with the pleurodesis outcome after 1 month. Fourteen out of 40 patients were failed to pleurodese (35\%). Twenty-six out of 40 (65\%) had successful pleurodesis. This was based on radiological assessment after 1 month as described above.

In a recent study by Chopra et al. ${ }^{5}, 70$ patients with MPE in whom complete drainage was done with PM were evaluated. The aim was to determine the frequency of elevated $\mathrm{P}_{\mathrm{EL}}$ and its relation to post-thoracentesis radiographic findings. Postthoracentesis CXRs showed incomplete expansion in 54\% of patients. This higher prevalence of unexpandable lung was explained by the investigators due to the rigorous requirement in their study that necessitated at least $90 \%$ apposition of visceral and parietal pleura to define lung expansion ${ }^{5}$.

In our study, $\mathrm{P}_{\mathrm{EL}}$ was significantly higher in the failed pleurodesis group $(\mathrm{p}<0.001)$ (Figure 2$)$. The $\mathrm{P}_{\mathrm{EL}}$ was a significant predictor variable in differentiating between failed and

Table 2. Pleural effusion characteristics in both groups

\begin{tabular}{|lccc|}
\hline \multicolumn{1}{|c|}{ Variable } & Failed pleurodesis & Successful pleurodesis & p-value \\
\hline Albumin, g/dL & $2.42 \pm 0.70$ & $2.47 \pm 0.58$ & $0.81^{*}$ \\
\hline Protein, g/dL & $4.56 \pm 1.21$ & $4.41 \pm 0.91$ & $0.68^{*}$ \\
\hline $\mathrm{LDH}, \mathrm{IU} / \mathrm{L}$ & $694 \pm 487$ & $555 \pm 535$ & $0.41^{*}$ \\
\hline $\mathrm{pH}$ & $7.24 \pm 0.08$ & $7.39 \pm 0.10$ & $<0.001^{*}$ \\
\hline Glucose, mg/dL & $108.50 \pm 85.20$ & $95.80 \pm 54.90$ & $0.62^{*}$ \\
\hline Predominant cell in cytology & & & $0.61^{\dagger}$ \\
\hline Mesothelial cell & $1(7.1)$ & $3(11.5)$ & \\
\hline Malignant cell & $4(28.6)$ & $6(23)$ & $0.86^{\dagger}$ \\
\hline Lymphocytes & $2(14.3)$ & $8(30.8)$ & \\
\hline No predominant cell & $7(50)$ & $9(34.6)$ & \\
\hline Thoracoscopic findings & & $3(11.5)$ & \\
\hline Masses & $2(14.3)$ & $13(50)$ & $0.14^{\dagger}$ \\
\hline Nodules & $7(50)$ & $2(7.7)$ & \\
\hline Thick pleura & $2(14.3)$ & & \\
\hline Nodules and thick pleura & $3(21.4)$ & $19(73.1)$ & \\
\hline Pathology & & & \\
\hline Mesothelioma & $7(50)$ & & \\
\hline Metastatic & $7(50)$ & & \\
\hline
\end{tabular}

Values are represented as mean \pm standard deviation or number (\%).

*Independent t test. ${ }^{\dagger}$ Chi-square test, p-value considered significant if $<0.05$.

LDH: lactate dehydrogenase. 


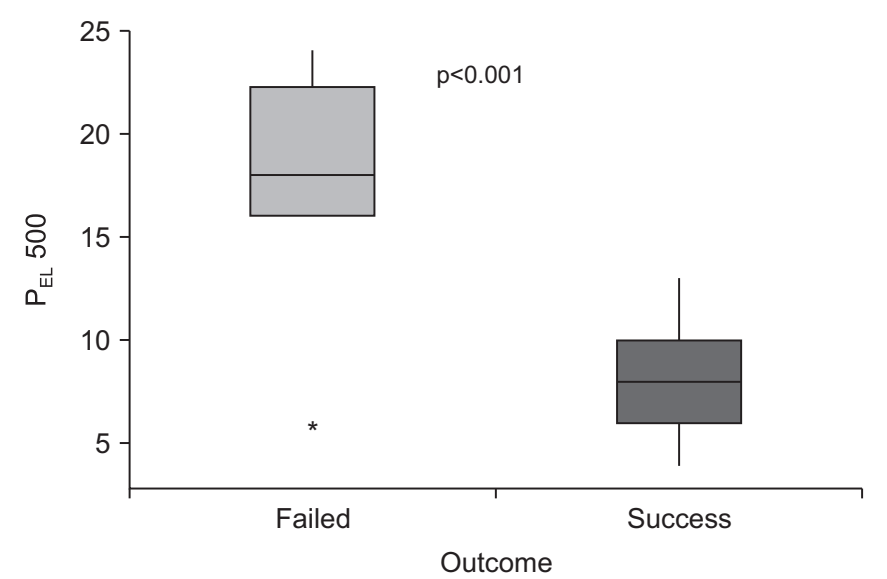

Figure 2. Pleural elastance in both groups. $\mathrm{P}_{\mathrm{EL}}$ : pleural elastance.

successful pleurodesis (AUC 94\%, $\mathrm{p}<0.001$ ). At cutoff point $>14.5$, the sensitivity and specificity were $93 \%$ and $100 \%$, respectively (Table 3 ).

In an early study, Lan et al. ${ }^{6}$ reported that elevated $\mathrm{P}_{\mathrm{EL}} \geq 19$ $\mathrm{cm} \mathrm{H}_{2} \mathrm{O} / \mathrm{L}$ during removal of $500 \mathrm{~mL}$ of fluid was associated with $79 \%$ sensitivity and $94 \%$ specificity for NEL.

In the study done by Chopra et al. ${ }^{5}$, patients with normal $\mathrm{P}_{\mathrm{EL}}$ $\left(\leq 14.5 \mathrm{H}_{2} \mathrm{O} / \mathrm{L}\right.$ ) had significantly higher rate of complete lung expansion in CXR. On the other hand, patients with elevated $\mathrm{P}_{\mathrm{EL}}\left(>14.5 \mathrm{H}_{2} \mathrm{O} / \mathrm{L}\right)$ had significantly higher rate of incomplete lung expansion in CXR than those with normal elastance ${ }^{5}$.

However, one-third of patients in that cohort had discordance between post-drainage CXR and PM findings. Therefore, they postulated that CXR alone is inadequately sensitive and inadequately specific to detect high $\mathrm{P}_{\mathrm{EL}}$. Additionally, $\mathrm{PM}$ was found to be an important adjunctive measurement in term of prediction of pleurodesis outcome ${ }^{5}$.

A recent EDIT (Elastance-Directed Intrapleural Catheter or Talc Pleurodesis in Malignant Pleural Effusion) trial that is currently undergoing was based on importance of PM in personalizing the management of malignant pleural effusion ${ }^{7}$.

A pilot study of the EDIT involved $\mathrm{P}_{\mathrm{EL}}$ assessment during large-volume thoracentesis. Patients with $\mathrm{P}_{\mathrm{EL}}>14.5 \mathrm{~cm} \mathrm{H}_{2} \mathrm{O}$ / $\mathrm{L}$ were allocated to immediately receive an indwelling pleural catheter, the remainder underwent standard care that involved immediate drain placement for talc pleurodesis. In the published pilot study, high $\mathrm{P}_{\mathrm{EL}}$ was detected in seven of 13 patients (54\%) with $100 \%$ sensitivity and $67 \%$ specificity for NEL ${ }^{7}$.

All of the above-mentioned data paves a new pathway of an elastance-directed MPE management. And put forth the concept of personalized treatment protocols into clinical practice.

In concordance with Ferreiro et al. ${ }^{8}$, we did not find significant statistical difference between succeeded and failed cases in relation to the value of pleural fluid total proteins nor the value of pleural fluid albumin.

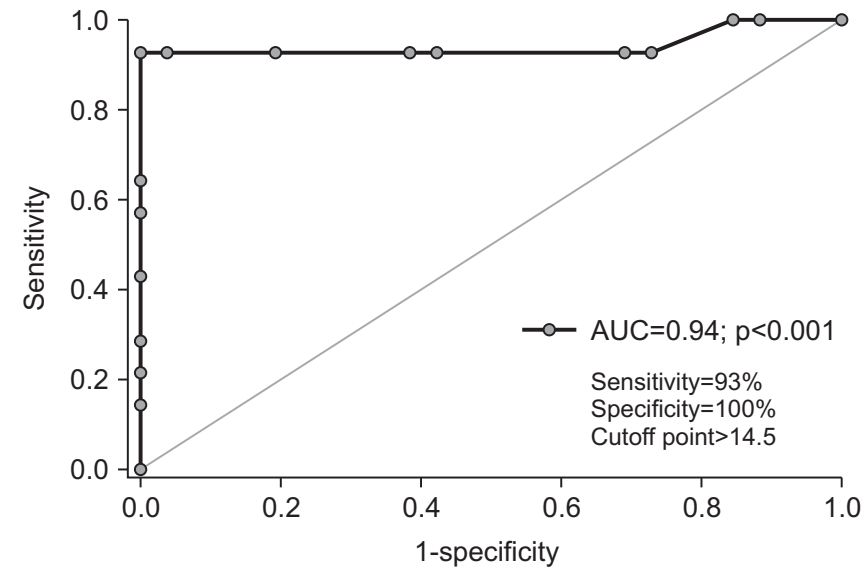

Figure 3. Receiver operating characteristic curve of pleural elastance. AUC: area under curve.

Different investigators addressed the implication of pleural fluid glucose to predict successful pleurodesis. Pantazopoulos et al. ${ }^{9}$, reported that lower level of pleural fluid glucose was associated with pleurodesis failure, with a cutoff point of $65 \mathrm{mg} /$ dL had a high sensitivity (90.7\%) with an acceptable specificity $(76.8 \%)(\mathrm{p}<0.001)$. Heffner et al. ${ }^{10}$, had similar results and reported a cutoff points that discriminated failure from success $72 \mathrm{mg} / \mathrm{dL}$. However, in the present study, we were not able to find a significant difference between the two groups in relation to the value of pleural fluid glucose. This may be attributed to the high prevalence of diabetes in the studied patients; thus, they had elevated levels of glucose in serum and their pleural fluid.

In the present study, the mean value of pleural fluid LDH in the patients with succeeded pleurodesis was $555 \mathrm{IU} / \mathrm{L}$, while in failed cases, the mean value was $694 \mathrm{IU} / \mathrm{L}$. Although LDH mean value in failed cases was higher than succeeded cases, the difference between them did not reach statistical significance $(\mathrm{p}=0.41)$. These results were in concordance with the results obtained in the study performed by Ferreiro et al. ${ }^{8}$, Yildirim et al. ${ }^{11}$, and Rafei et al. ${ }^{12}$, who found no correlation between the values of pleural fluid LDH and the success or failure of pleurodesis.

In the studied patients, pleural fluid $\mathrm{pH}$ was significantly lower in the failed group. This was in agreement with Yildirim et al. ${ }^{11}$, who found a cutoff point 7.34 below which pleurodesis is most likely to fail. Pleural fluid $\mathrm{pH}$ is determined by the acids generated from glucose metabolism of cells within the pleural space, as well as the efflux of those acids and the influx of glucose across the pleural membranes. Diffusion across the pleura can be affected in acute inflammatory states (e.g., infection), chronic fibrotic conditions (e.g., rheumatoid pleurisy) and tumor infiltration in pleural malignancies. Due to abnormal pleura in patients with low $\mathrm{pH}$ effusions, the rate of transport of $\mathrm{CO}_{2}$ and lactic acid out of pleural space is slowed 
Table 3. A brief comparison of the most commonly used sclerosing agents

\begin{tabular}{|c|c|c|}
\hline Sclerosant agent & Chemical nature & Remarks \\
\hline Talc & Hydrated magnesium silicate & $\begin{array}{l}\text { Most effective } \\
\text { Most commonly used } \\
\text { High success rate }^{13}\end{array}$ \\
\hline Doxycycline & Antibiotic of tetracycline group & Lower success rate than talc ${ }^{14}$ \\
\hline Silver nitrate & Topical antibiotic & $\begin{array}{l}\text { Good safety profile } \\
\text { Equal in efficacy when compared with talc and doxycycline }{ }^{15}\end{array}$ \\
\hline Bleomycin & Cytotoxic, chemotherapeutic drug & Less commonly used due to systemic toxicity and high cost ${ }^{13}$ \\
\hline
\end{tabular}

and accumulation occurs resulting in decreased pleural fluid $\mathrm{pH}$.

This study revealed malignant mesothelioma in 26 patients (65\%) while 14 patients (35\%) had metastatic tumors. This was in agreement with Yildirim et al. ${ }^{11}$, who found that pleural mesothelioma was the most common malignancy producing MPE.

In the current study, doxycycline was used as a sclerosant agent due to its availability and low cost. However, several chemical irritants have been used to induce pleurodesis. The most commonly used are talc, doxycycline, silver nitrate, and bleomycin (Table 3).

A limitation of the current study is that $\mathrm{P}_{\mathrm{EL}}$ was calculated over the first $500 \mathrm{~mL}$ of pleural drainage and there was a lack of evaluation of the entire pressure volume curve. This may have missed patients with biphasic $\mathrm{P} / \mathrm{V}$ curve with high terminal $P_{\mathrm{EL}}$.

In summary, our study highlights the importance of $\mathrm{P}_{\mathrm{EL}}$ measurement in patients with MPE to anticipate pleurodesis outcome. Elastance of less than $14.5 \mathrm{~cm} \mathrm{H}_{2} \mathrm{O}$ predicts an expandable lung and hence could be treated by intercostal tube insertion and injection of pleurodesis agents. On the other side, elastance of more than $14.5 \mathrm{~cm} \mathrm{H}_{2} \mathrm{O}$ indicates an unexpandable lung and hence these patients should be managed differently, as indwelling pleural catheter would be the best treatment option.

Further studies are needed to confirm these findings. In addition, finding simpler ways for measuring $\mathrm{P}_{\mathrm{EL}}$ are warranted to facilitate its implication in the current medical practice.

\section{Authors' Contributions}

Conceptualization: Assal HH, Masoud HH. Methodology: Ahmed AA. Formal analysis: Assal HH, Ahmed AA. Data curation: El-Zorkany MM. Software: El-Zorkany MM. Validation: Masoud HH. Investigation: Ahmed AA. Writing - original draft preparation: Ahmed AA. Writing - review and editing: Assal $\mathrm{HH}$, Masoud HH, El-Zorkany MM. Approval of final manuscript: all authors.

\section{Conflicts of Interest}

No potential conflict of interest relevant to this article was reported.

\section{Funding}

No funding to declare.

\section{References}

1. Psallidas I, Kalomenidis I, Porcel JM, Robinson BW, Stathopoulos GT. Malignant pleural effusion: from bench to bedside. Eur Respir Rev 2016;25:189-98.

2. Bibby AC, Dorn P, Psallidas I, Porcel JM, Janssen J, Froudarakis $\mathrm{M}$, et al. ERS/EACTS statement on the management of malignant pleural effusions. Eur J Cardiothorac Surg 2019;55: 116-32.

3. Pannu JK, Lentz RJ. Discordance between pleural elastance and postthoracentesis chest radiograph: putting pressure on pleurodesis trials. Chest 2020;157:249-50.

4. Huggins JT, Sahn SA, Heidecker J, Ravenel JG, Doelken P. Characteristics of trapped lung: pleural fluid analysis, manometry, and air-contrast chest CT. Chest 2007;131:206-13.

5. Chopra A, Judson MA, Doelken P, Maldonado F, Rahman NM, Huggins JT. The relationship of pleural manometry with postthoracentesis chest radiographic findings in malignant pleural effusion. Chest 2020;157:421-6.

6. Lan RS, Lo SK, Chuang ML, Yang CT, Tsao TC, Lee CH. Elastance of the pleural space: a predictor for the outcome of pleurodesis in patients with malignant pleural effusion. Ann Intern Med 1997;126:768-74.

7. Martin GA, Tsim S, Kidd AC, Foster JE, McLoone P, Chalmers A, et al. Pre-EDIT: a randomized feasibility trial of elastancedirected intrapleural catheter or talc pleurodesis in malignant pleural effusion. Chest 2019;156:1204-13.

8. Ferreiro L, San Jose E, Gude F, Valdes L. Pleural fluid analysis and pleural elastance as predictors of response to pleurodesis in patients with malignant pleural effusion. Arch Bronconeu- 
mol 2018;54:163-5.

9. Pantazopoulos I, Xanthos T, Vlachos I, Kakoulas Z, Stroumpoulis K, Chalkias A, et al. Pleural fluid glucose: a predictor of unsuccessful pleurodesis in a preselected cohort of patients with malignant pleural effusion. J BUON 2014;19: 1018-23.

10. Heffner JE, Nietert PJ, Barbieri C. Pleural fluid pH as a predictor of pleurodesis failure: analysis of primary data. Chest 2000;117:87-95.

11. Yildirim H, Metintas M, Ak G, Metintas S, Erginel S. Predictors of talc pleurodesis outcome in patients with malignant pleural effusions. Lung Cancer 2008;62:139-44.

12. Rafei H, Jabak S, Mina A, Tfayli A. Pleurodesis in malignant pleural effusions: outcome and predictors of success. Integr
Cancer Sci Ther 2015;2:216-21.

13. Diacon AH, Wyser C, Bolliger CT, Tamm M, Pless M, Perruchoud AP, et al. Prospective randomized comparison of thoracoscopic talc poudrage under local anesthesia versus bleomycin instillation for pleurodesis in malignant pleural effusions. Am J Respir Crit Care Med 2000;162:1445-9.

14. Park EH, Kim JH, Yee J, Chung JE, Seong JM, La HO, et al. Comparisons of doxycycline solution with talc slurry for chemical pleurodesis and risk factors for recurrence in South Korean patients with spontaneous pneumothorax. Eur J Hosp Pharm 2019;26:275-9.

15. Bucknor A, Harrison-Phipps K, Davies T, Toufektzian L. Is silver nitrate an effective means of pleurodesis? Interact Cardiovasc Thorac Surg 2015;21:521-5. 